\title{
MODEL GENERATION FOR ANALYSIS WITH MOdELICA BASED ON THE ATL MODEL TRANSFORMATION LANGUAGE
}

\author{
RANDIC, M.; BlaskOVIC, B. \& DEMBITZ, S.
}

Abstract: We are currently witnessing an increasing usage of models in developing software systems. The intention is to put model to be actively integrated into software engineering and tool integration processes. In this context, model transformation appears to be a central and extremely useful operation for model handling. In this paper we propose usage of the model transformation techniques for automated generation of models that can be analyzed with Modelica simulation tool. Transformations are based on source and target metamodels written in KM3 language as well as on transformation rules. We explain development of all relevant specifications in the paper. Presented approach considerably improves process of Modelica models building in cases where an initial, object-oriented model of a system intended for simulation exists. Moreover simulation model generation means more efficiency in simulation engineering. In described transformations we use the ATLAS Transformation Language, ATL together with the ATL Development Tools, $A D T$ implemented as standard Eclipse plugins. Presented example refers to AC circuit analysis problem domain, but results of our research can be applied generally, in any domain.

Key words: model transformation, transformation language, meta-model, metameta modeling, Modelica, AC circuit analysis
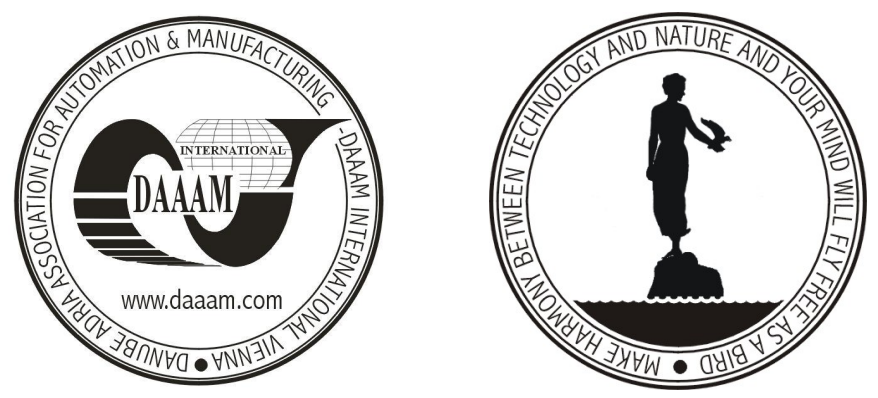

Authors' data: Doc.dr.sc. Randic, M[irko]; Prof.dr.sc. Blaskovic, B[runo]; Prof.dr.sc. Dembitz, S[andor], Faculty of Electrical Engineering and Computing, Unska 3, 10000 Zagreb, Croatia, mirko.randic@fer.hr, bruno.blaskovic@fer.hr, sandor.dembitz@fer.hr

This Publication has to be referred as: Randic, M.; Blaskovic, B. \& Dembitz, S. (2007). Model Generation for Analysis with Modelica Based on the Atl Model Transformation Language, Chapter 24 in DAAAM International Scientific Book 2007, B. Katalinic (Ed.), Published by DAAAM International, ISBN 3-901509-60-7, ISSN 1726-9687, Vienna, Austria

DOI: $10.2507 /$ daaam.scibook.2007.24 